\title{
Perceptions of students in health and molecular life sciences regarding pharmacogenomics and personalized medicine
}

Lejla Mahmutovic ${ }^{1}$, Betul Akcesme ${ }^{1,2}$, Camil Durakovic ${ }^{1}$, Faruk Berat Akcesme ${ }^{1,3}$, Aida Maric ${ }^{1}$, Muhamed Adilovic ${ }^{1}$, Nour Hamad ${ }^{1}$, Matthias Wjst ${ }^{4}$, Oliver Feeney ${ }^{5}$ and Sabina Semiz ${ }^{1 *}$

\begin{abstract}
Background: Increasing evidence is demonstrating that a patient's unique genetic profile can be used to detect the disease's onset, prevent its progression, and optimize its treatment. This led to the increased global efforts to implement personalized medicine (PM) and pharmacogenomics $(P G)$ in clinical practice. Here we investigated the perceptions of students from different universities in Bosnia and Herzegovina (BH) towards PG/PM as well as related ethical, legal, and social implications (ELSI). This descriptive, cross-sectional study is based on the survey of 559 students from the Faculties of Medicine, Pharmacy, Health Studies, Genetics, and Bioengineering and other study programs.

Results: Our results showed that $50 \%$ of students heard about personal genome testing companies and $69 \%$ consider having a genetic test done. A majority of students (57\%) agreed that PM represents a promising healthcare model, and $40 \%$ of students agreed that their study program is well designed for understanding PG/PM. This latter opinion seems to be particularly influenced by the field of study $(7.23, \mathrm{Cl} 1.99-26.2, p=0.003)$. Students with this opinion are also more willing to continue their postgraduate education in the PM $(\mathrm{OR}=4.68, \mathrm{Cl} 2.59-8.47, p<0.001)$. Furthermore, 45\% of students are aware of different ethical aspects of genetic testing, with most of them (46\%) being concerned about the patient's privacy.

Conclusions: Our results indicate a positive attitude of biomedical students in Bosnia and Herzegovina towards genetic testing and personalized medicine. Importantly, our results emphasize the key importance of pharmacogenomic education for more efficient translation of precision medicine into clinical practice.
\end{abstract}

Keywords: Precision medicine, Pharmacogenomics, Education, Ethical, legal, and social issues, Survey

\section{Background}

Personalized or precision medicine (PM) refers to an innovative approach to the disease diagnosis and treatment by considering differences in people's genetic background, lifestyle, and environment [1-3]. Importantly, it has the potential to shape many if not all aspects of clinical care from prevention and early diagnosis to treatment of disease $[4,5]$. Pharmacogenomics (PG)

\footnotetext{
* Correspondence: ssemiz@ius.edu.ba

${ }^{1}$ Faculty of Engineering and Natural Sciences, International University of Sarajevo, Hrasnicka cesta 15, 71210 llidza, Sarajevo, Bosnia and Herzegovina Full list of author information is available at the end of the article
}

studies individuals' genetic material in order to determine whether that person would benefit from a drug, require a different dose, or experience side effects, and as such is considered as an essential tool in personalized medicine $[1,6]$. The successful completion of the Human Genome Project in 2003 was a first crucial step towards personalized medicine [7] and that eventually led to the Precision Medicine Initiative in the USA in 2015 to advance biomedical research in PM and facilitate its transition to clinical care [8-10]. In order to ensure the benefits of personalized diagnosis and treatment, the Food and Drug Administration (FDA) has

(c) The Author(s). 2018 Open Access This article is distributed under the terms of the Creative Commons Attribution 4.0 International License (http://creativecommons.org/licenses/by/4.0/), which permits unrestricted use, distribution, and 
listed about 140 drugs with pharmacogenetic/pharmacogenomic (PG) information included in their labeling [9, 11]. Importantly, the identification of genetic variants by PG tests increases the prediction regarding drug efficacy and adverse reactions $[10,12,13]$. The guidelines provided by the Pharmacogenomics Knowledgebase (PharmGKB at https://www.pharmgkb.org/) and the Clinical Pharmacogenomics Implementation Consortium (CPIC at https:// cpicpgx.org/) are important educational and clinical resources for the healthcare professionals interested in introducing PG tests in their patient care.

Previous studies have shown that many physicians and pharmacists have positive attitudes towards the clinical application(s) of PG/PM [14, 15]. However, it appears that an inadequate knowledge and experience among some physicians and other healthcare professionals are the key drawbacks in more efficient clinical application of pharmacogenomics $[14,16-18]$, suggesting that it would be pertinent to introduce more PG topics in their professional education.

There are also many additional challenges that have to be addressed in order to facilitate its broader clinical implementation [19-21]. For example, the ethical, legal, and social implications (ELSI) of personalized medicine, such as informed consent, patient privacy, confidentiality, safety monitoring, reporting of adverse events, patient-centered practices, and other potential conflicting interests, have been addressed in existing bioethical analyses [20, 22-24]. However, further ethical implications associated with personalized medicine are emerging, for example, where it can be observed that different ethnicities may have different response to drugs [25-27]. Furthermore, some bioethicists are also concerned about the increased trend of human genome sequencing, processing, and storing of databases, private genetic bio/databanks, as well as about the increasingly popular direct-to-consumer (DTC) genetic tests, incidental (unsolicited) non-PG findings, potential health disparities, and other socioeconomic barriers in a broad PG application [28-32].

It is also important to mention here an issue which is often overlooked and that is of the fairness (or lack thereof) related to how the benefits of pharmacogenetic research, such as an increasing number of genomic advances relevant to disease prevention, diagnosis, and treatment [3] together with the decreasing costs of genetic testing [33], are currently being shared at the global level. A recent study performed by Manolio et al. [34] identified the major barriers to global implementation of genomic medicine, including high costs and/or lack of reimbursement and limited access to reliable standardized genotyping or sequencing platforms. Previous studies concluded that countries with limited research sources should have a chance to also express their opinions in making global decisions regarding public access and benefits from the commercialized products, such as (pharmaco) genetic tests [35]. Transnational collaboration through the large research consortia and sharing information in the areas of health information technology, pharmacogenomics, education, professional development, and policy and regulatory issues seems to be pertinent for the future efficient clinical implementation of personalized medicine at the global level [34]. Increasing evidence is demonstrating different views and attitudes regarding PG testing, including patients' concerns about privacy, discrimination, quality of care, and value of the relationship between patient and physician [32] Recently, several survey-based studies have been performed in order to assess the knowledge and awareness of health science students in the area of pharmacogenomics, personalized medicine, and bioethics [36-39]. Results of these studies demonstrated that health science students' knowledge and appreciation of PG is very important for optimal patient care. They should have the necessary skills and knowledge to make more rational therapy decisions based on patients' genetic information [38].Thus, education and raising awareness of biomedical students are of key importance for the future practice of precision medicine.

More than a decade ago, the International Society of Pharmacogenomics proposed recommendations regarding PG education standards to the medical, pharmacy, and health schools globally [40]. Consequently, many medical and pharmacy schools around Europe adopted these recommendations and included PG topics in their curricula [41-45], while only a few programs have been evaluated.

This is the first study of students' perception of pharmacogenomics in Bosnia and Herzegovina (BH). Although there are a few pharmacogenetic studies that have been performed in $\mathrm{BH}$ [46-50], an inadequate understanding of pharmacogenomics, expertise, and limited resources of the healthcare system in this middle-income country appears to represent the major challenges in clinical application of PG. Since the views of $\mathrm{BH}$ students have not been investigated yet on this topic, it is pertinent to understand the current status and needs for pharmacogenomic education in order to develop appropriate educational and training programs among professionals and students in health and molecular life sciences. Here we investigate the awareness and attitudes of health science (medical, pharmacy, health studies) and molecular life science (genetics and bioengineering) students in $\mathrm{BH}$ towards genetic testing, pharmacogenomics, and personalized medicine. As a second outcome, different ethical, legal, and social issues (ELSI) of personalized treatment have been also investigated. While health and molecular life science university students are not representative of the population as a whole, given their roles as the future medical doctors, 
nurses, pharmacists, and other health care professionals in $\mathrm{BH}$ society, it is important to capture their views.

\section{Methods}

This descriptive, cross-sectional study was done using online and hard copy questionnaires (survey is accessible as Additional file 1) between the second and eighth week of the spring semester in February and March 2016. Surveys were distributed by the teachers during a class or they were accessed online. Eligible participants included current students from several universities in Bosnia and Herzegovina (BH) located in four different cities, including Sarajevo, Tuzla, Mostar, and Bihac. The total number of 559 students participating in the survey involved students from the Faculty of Pharmacy, Faculty of Medicine, Faculty of Health Studies (FHS), Genetics and Bioengineering (GBE), as well as students from other non-health science (HS) and non-molecular life science (MLS)-related faculties.

The survey consisted of four clusters from a total of 33 questions on the following: (i) demographic and professional characteristics of the participants, (ii) participants' diseases and treatment, (iii) awareness and attitudes towards genetic testing and personalized medicine approach, and (iv) challenges towards genetic tests, PG, and its clinical application. Key definitions of genetic testing, personalized medicine, and pharmacogenomic/pharmacogenetic test were provided to the participants in the instruction section of the survey. All survey questions were consistent across all participating faculties. The survey included yes/no/I do not know (not sure) questions. In addition, the survey asked for levels of agreement with various statements using a Likert scale (i.e., agree, disagree, no opinion, neutral) and also offered multiple choice questions. Before being sent to students for the study, this questionnaire was reviewed by three experts from various backgrounds (clinical genetics, genomics, genetic counseling, genetic education, ethics, and social sciences). Along with the survey, an introductory cover page was attached describing the purpose and objectives of the study and inviting the students to participate in the study. Participants were assured their identity and all data are confidential. Participation was voluntary, and the study was approved by the Ethical Committee of the International University of Sarajevo.

\section{Statistical analysis}

All categorical variables including participants' demographics, professional information, and answers to questions regarding the perceptions about PG and PM were expressed as frequencies and percentages. Descriptive analysis was performed by using chi-square test and ANOVA for categorical variables. In addition, the binary logistic regression was performed in order to assess association between question of interest and hypothetically related covariates, while adjusting for age, gender, and level of education. In model I, we present this association prior to adjustment; in model II, we analyzed this association adjusted for age and gender, while model III additionally included an adjustment for the level of education. Odds ratio (OR) and corresponding 95\% confidence intervals $(\mathrm{CI})$ were computed, using a significance level of 5\% for all statistical tests. Statistical analysis was performed by using IBM Statistical Package for Social Sciences (IBM SPSS ${ }^{\circ} 23$ ).

\section{Results}

\section{Participants' characteristics}

Table 1 summarizes the students' demographics characteristics and professional information. The response rate was calculated for all students who completed the survey ( $N=559,10 \%$ response rate), including students from the Faculty of Pharmacy $(N=183)$, students from the Faculty of Medicine $(N=158)$, students from the Faculty of Health Studies $(N=64)$, students from the Genetics and Bioengineering $(N=66)$, and 88 students from other non-HS- and non-MLS-related study programs (architecture; psychology; industrial, mechanical, and electrical engineering; computer sciences; law; political sciences; and visual arts) $(N=88)$. The majority of participants were female $(71 \%)$ and undergraduate students $(N=398,84 \%)$, while $12 \%(N=60)$ were attending Master and $3 \%$ $(N=13) \mathrm{PhD}$ programs, with age ranging from 19 to 26 years old (86\%).

\section{Students' attitudes towards pharmacogenetic testing and personalized medicine}

Participants' responses to almost all survey questions regarding their awareness and attitudes towards genetic testing, pharmacogenomics, personalized medicine, and corresponding ELSI are shown in the tables, with selected ones that are further elaborated in the discussion. As shown in Table 2, about $30-40 \%$ of participants from medicine, pharmacy, health studies, and genetics and bioengineering experienced that a particular drug did not work for them, while about $15-25 \%$ of these students had an adverse drug reaction. When asked about personal genome testing companies, about half of the participants from all HS and MLS faculties responded that they have heard about these companies and the majority of students $(69 \%)$ showed an interest in having a genetic test done. About $40 \%$ of students would also consider contacting a personal genome testing company and ordering a PG test. The majority of students (70\%) believe that genes moderately influence their health, with $13 \%$ of them thinking that genes completely affect it. When asked would they take the drug if a PG test revealed that prescribed drug would either be ineffective 
Table 1 Students' demographic characteristics and professional information

\begin{tabular}{|c|c|c|c|c|c|c|c|}
\hline & Total & $\begin{array}{l}\text { Faculty of } \\
\text { Pharmacy }\end{array}$ & $\begin{array}{l}\text { Faculty of } \\
\text { Medicine }\end{array}$ & $\begin{array}{l}\text { Genetics and } \\
\text { Bioengineering }\end{array}$ & $\begin{array}{l}\text { Faculty of } \\
\text { Health Studies }\end{array}$ & $\begin{array}{l}\text { Non-ML\&HS } \\
\text { faculties }\end{array}$ & $p^{*}$ \\
\hline \multicolumn{8}{|l|}{ Gender } \\
\hline Male & $153(29)^{a}$ & $25(15)$ & $46(29)$ & $16(26)$ & $19(29)$ & $47(54)$ & \multirow[t]{3}{*}{$<0.01$} \\
\hline Female & $382(71)$ & $140(85)$ & $110(71)$ & $46(74)$ & $46(71)$ & $40(46)$ & \\
\hline Total & 535 & 165 & 156 & 62 & 65 & 87 & \\
\hline \multicolumn{8}{|l|}{ Age } \\
\hline$<19$ & $37(6.8)$ & - & - & $19(30)$ & $10(15)$ & $8(9)$ & \multirow[t]{7}{*}{$<0.01$} \\
\hline $19-26$ & $465(86)$ & $141(85)$ & $154(97)$ & $44(70)$ & $54(82)$ & $72(82)$ & \\
\hline $26-40$ & $37(6.8)$ & $24(14)$ & $4(2)$ & - & $2(3)$ & $7(8)$ & \\
\hline $41-50$ & $1(0.2)$ & - & - & - & - & $1(1)$ & \\
\hline $51-60$ & $1(0.2)$ & $1(1)$ & - & - & - & - & \\
\hline$>60$ & $1(0.2)$ & - & $1(1)$ & - & - & - & \\
\hline Total & 542 & 166 & 159 & 63 & 66 & 88 & \\
\hline \multicolumn{8}{|l|}{ Level of education } \\
\hline Less than high school & $3(1)$ & - & $1(1)$ & - & - & $2(2)$ & \multirow[t]{4}{*}{$<0.01$} \\
\hline $\mathrm{BSC}$ & $398(84)$ & $89(63)$ & $129(95)$ & $56(97)$ & $60(97)$ & $64(82)$ & \\
\hline MSC & $60(12)$ & $46(33)$ & $4(3)$ & $2(3)$ & $2(3)$ & $6(8)$ & \\
\hline PhD & $13(3)$ & $6(4)$ & $1(1)$ & - & - & $6(8)$ & \\
\hline Total & 474 & 141 & 135 & 58 & 62 & 78 & \\
\hline
\end{tabular}

ML\&HS, Molecular Life and Health Science;

${ }^{*}$ Chi-square test, Bonferroni-adjusted $p$ values

apercentage (\%)

or cause severe side effects, about $40 \%$ of all students responded that they would accept the test result and take the drug only if the disease might be life-threatening (Table 2). Furthermore, more than half of all students (57\%) agreed that personalized medicine represents a promising healthcare model.

The level of awareness about companies offering PG tests appears to be similar between medicine and pharmacy students (not significantly different; see Additional file 2). Students from the Faculty of Health Studies are less aware of genome testing companies than their colleagues from the medicine and pharmacy $(p=0.010$ and $p=0.025$, respectively). A significantly lower number of these students agreed that PM represents the new and promising healthcare model as compared to the pharmacy and genetics students $(p<0.01$ and $p=0.01$, respectively; Additional file 3).

As shown in Table 2, respondents from the other non-health and non-molecular life sciences-related studies are generally aware that genes affect their health, and about half of them agree that personalized medicine represents a new and promising healthcare model. Furthermore, the majority of these students $(60 \%)$ from non-HS and non-MLS faculties would consider having genetic test done to find out what illnesses they might develop in the future. However, their awareness of personal genome testing companies is significantly lower as compared to their peers from medicine, pharmacy, and genetics $(p<0.01, p<0.01$, and $p=0.02$, respectively; Additional file 2). In addition, as shown in Table 2, a lower number of these students (23\%) from the non-health and non-molecular life science studies would consider contacting a personal genome testing company to order a PG test, as compared to the number of students from pharmacy (52\%), health sciences (44\%), and GBE (45\%).

Our results of logistic regression analysis, performed to determine which independent variables were the strongest predictors of the specific students' responses, demonstrated belief that genes influence health in moderate to complete extent. Students with this belief would consider having a genetic test done to find out which illnesses they might develop in the future $(\mathrm{OR}=3.02$, CI $1.16-7.85, p=0.024$ ) (Table 3). This association does not appear to be affected by age, gender, and/or levels of education. Furthermore, our results demonstrated that those students who agreed that personalized medicine represents a new and promising healthcare model were also willing to do a genetic test, as compared to those who think the opposite (OR $=3.11$, CI 1.60-6.06, $p=0.001)$. In addition, students who are ready to make necessary changes in their lifestyle to reduce disease risk would also consider having a genetic test done to know their genetic tendency to develop a disease $(\mathrm{OR}=0.198$, CI 0.114 $0.283, p=0.001$ ). Our results also indicated that students' 
Table 2 Students' attitudes towards pharmacogenetic testing and personalized medicine

\begin{tabular}{|c|c|c|c|c|c|c|c|}
\hline & Total & $\begin{array}{l}\text { Faculty of } \\
\text { Pharmacy }\end{array}$ & $\begin{array}{l}\text { Faculty of } \\
\text { Medicine }\end{array}$ & $\begin{array}{l}\text { Genetics } \\
\text { and Bioeng. }\end{array}$ & $\begin{array}{l}\text { Faculty of } \\
\text { Health Studies }\end{array}$ & $\begin{array}{l}\text { Non- ML\&HS } \\
\text { faculties }\end{array}$ & $p^{*}$ \\
\hline \multicolumn{8}{|c|}{ Have you heard about personal genome testing companies? } \\
\hline Yes & $271(50)^{a}$ & $95(57)$ & $101(64)$ & $29(44)$ & $23(37)$ & $23(27)$ & \multirow[t]{4}{*}{$<0.01$} \\
\hline No & $136(26)$ & $39(23)$ & $26(16)$ & $25(38)$ & $22(36)$ & $24(18)$ & \\
\hline Do not know & $131(24)$ & $32(20)$ & $31(20)$ & $12(18)$ & $17(27)$ & $39(31)$ & \\
\hline Total & 538 & 166 & 158 & 66 & 62 & 86 & \\
\hline \multicolumn{8}{|c|}{ To what extent do you think genes influence your health? } \\
\hline Completely & $74(13)$ & $30(18)$ & $18(11)$ & $8(13)$ & $7(11)$ & $11(13)$ & \multirow[t]{5}{*}{$<0.01$} \\
\hline Moderately & $375(69)$ & $129(78)$ & $132(80)$ & $43(68)$ & $36(56)$ & $35(41)$ & \\
\hline Not at all & $37(7)$ & $1(1)$ & $10(6)$ & $4(6)$ & $1(2)$ & $21(24)$ & \\
\hline Do not know & $58(11)$ & $6(3)$ & $5(3)$ & $8(13 \%)$ & $20(31)$ & $19(22)$ & \\
\hline Total & 544 & 166 & 165 & 63 & 64 & 86 & \\
\hline \multicolumn{8}{|c|}{ Would you consider having a genetic test done to find out what illnesses you might develop in the future? } \\
\hline Yes & $374(69)$ & $138(83)$ & $101(64)$ & $45(68)$ & $38(59)$ & $52(60)$ & \multirow[t]{4}{*}{$<0.01$} \\
\hline No & $110(21)$ & $20(12)$ & $36(23)$ & $15(23)$ & $20(31)$ & $19(22)$ & \\
\hline Not sure & $56(10)$ & $8(5)$ & $20(13)$ & $6(9)$ & $6(10)$ & $16(18)$ & \\
\hline Total & 540 & 166 & 157 & 66 & 64 & 87 & \\
\hline \multicolumn{8}{|c|}{ Do you agree that personalized medicine represents a new and promising healthcare model? } \\
\hline Agree & $295(57)$ & $116(70)$ & $83(52)$ & $31(74)$ & $24(37)$ & $41(48)$ & \multirow[t]{3}{*}{$<0.01$} \\
\hline Disagree & $62(12)$ & $14(8)$ & $17(11)$ & $1(2)$ & $10(16)$ & $20(23)$ & \\
\hline Not sure & $160(31)$ & $37(22)$ & $58(37)$ & $10(24)$ & $30(47)$ & $25(29)$ & \\
\hline Total & 517 & 167 & 158 & 42 & 64 & 86 & \\
\hline \multicolumn{8}{|c|}{ Have you ever had an adverse drug reaction? } \\
\hline Yes & $91(17)$ & $41(25)$ & $22(14)$ & $8(13)$ & $10(16)$ & $10(11)$ & \multirow[t]{5}{*}{$<0.01$} \\
\hline No & $328(61)$ & $82(51)$ & $112(71)$ & $45(69)$ & $42(67)$ & $47(54)$ & \\
\hline Do not know & $89(16)$ & $38(23)$ & $20(13)$ & $10(15)$ & $8(13)$ & $13(15)$ & \\
\hline I have never taken any medication & $29(6)$ & $2(1)$ & $4(2)$ & $2(3)$ & $3(5)$ & $18(20)$ & \\
\hline Total & 537 & 163 & 158 & 65 & 63 & 88 & \\
\hline \multicolumn{8}{|c|}{ Have you ever found that a particular drug did not work for you? } \\
\hline Yes & $184(34)$ & $67(41)$ & $47(30)$ & $26(39)$ & $25(39)$ & $19(22)$ & \\
\hline No & $226(42)$ & $69(42)$ & $76(49)$ & $25(38)$ & $25(39)$ & $31(35)$ & \\
\hline Do not know & $90(17)$ & $27(16)$ & $26(18)$ & $11(17)$ & $7(11)$ & $19(22)$ & \\
\hline I have never taken any medication & $37(6)$ & $2(1)$ & $5(3)$ & $4(6)$ & $7(11)$ & $19(22)$ & \\
\hline Total & 537 & 165 & 154 & 66 & 64 & 88 & \\
\hline
\end{tabular}

If a PG test revealed that prescribed drug would either be ineffective or cause severe side effects, would you take the drug anyway?

$\begin{array}{lllllll}\text { Take the drug anyway } & 62(12) & 17(10) & 38(23) & 6(10) & 9(14) & 2(2) \\ \text { Accept the test result and not take the drug } & 117(22) & 34(20) & 27(16) & 20(30) & 20(32) & 16(19) \\ \begin{array}{l}\text { Accept the test result and take the drug only if } \\ \text { the disease might be life-threatening }\end{array} & 207(39) & 79(48) & 61(37) & 24(36) & 15(24) & 28(33) \\ \text { Not sure } & 150(28) & 36(22) & 39(24) & 16(24) & 19(30) & 40(46) \\ \text { Total } & 536 & 166 & 165 & 66 & 63 & 66\end{array}$


Table 2 Students' attitudes towards pharmacogenetic testing and personalized medicine (Continued)

\begin{tabular}{|c|c|c|c|c|c|c|c|}
\hline & Total & $\begin{array}{l}\text { Faculty of } \\
\text { Pharmacy }\end{array}$ & $\begin{array}{l}\text { Faculty of } \\
\text { Medicine }\end{array}$ & $\begin{array}{l}\text { Genetics } \\
\text { and Bioeng. }\end{array}$ & $\begin{array}{l}\text { Faculty of } \\
\text { Health Studies }\end{array}$ & $\begin{array}{l}\text { Non- ML\&HS } \\
\text { faculties }\end{array}$ & $p^{*}$ \\
\hline \multicolumn{8}{|c|}{ Would you consider contacting a personal genome testing company and ordering a PG test for yourself? } \\
\hline Yes & $211(39)$ & $85(52)$ & $54(33)$ & $30(45)$ & $28(44)$ & $20(23)$ & \multirow[t]{3}{*}{0.01} \\
\hline No & $117(22)$ & $24(14)$ & $39(24)$ & $14(21)$ & $17(27)$ & $21(24)$ & \\
\hline Do not know & 210 & $57(34)$ & $69(43)$ & $22(34)$ & 18 (29) & $45(53)$ & \\
\hline Total & 538 & 166 & 162 & 66 & 63 & 86 & \\
\hline
\end{tabular}

ML\&HS Molecular Life and Health Science

${ }^{*}$ Chi-square test, Bonferroni-adjusted $p$ values

aPercentage (\%)

response on how much money they would be willing to spend to examine the effectiveness of a specific drug by using PG test was associated with their family monthly income $(\mathrm{OR}=0.229$, CI $0.065-0.392, p=0.006)$, regardless of the field of their study (OR $=0.033, \mathrm{CI}-0.075-0.141, p$ $=0.543)$. This association does not seem to be affected by age, gender, and/or levels of education.

\section{Importance of pharmacogenomics education}

Results presented in Table 4 demonstrated similar opinion between medical, pharmacy, and health studies students regarding their study curriculum and future plans related to PG. When asked about their study curriculum, $44 \%$ of pharmacy students, $51 \%$ of medical students, and $61 \%$ of health studies students agreed that their study

Table 3 Students' attitudes towards pharmacogenomics and personalized medicine

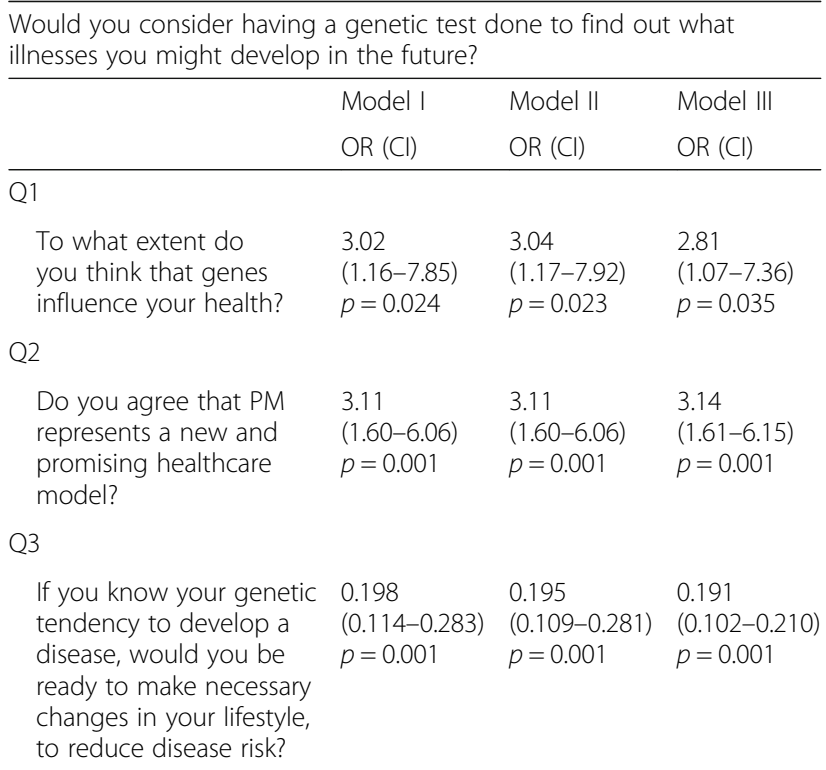

Model I: without adjustment; model II: adjusted to age and gender; model III: adjusted to age, gender, and level of education

Answer as a reference for Q1: completely; answer as a reference for Q2 and Q3: yes program is well designed for understanding PG. However, we found that only $20 \%$ of GBE students share this opinion, while $71 \%$ of them believe that PG should be an important part of their study curriculum $(p<0.01$, see Additional file 4). About $30 \%$ of respondents are mostly interested to learn about pharmacogenomics in general, its clinical examples and benefits, while about $20 \%$ of students would like to learn more about its corresponding ethical, legal, and social issues. More than half of GBE students (55\%) would like to continue their postgraduate education in the field of personalized medicine. Similarly, $74 \%$ of health studies students, $65 \%$ of pharmacy students, and $48 \%$ of medical students are also interested to continue their education in personalized medicine, which was significantly different as compared to the students from non-ML and non-HS study programs $(p<0.01$; see Additional file 5$)$. A similar finding was observed related to the students' opinion of PG position in their study curriculum, where significantly more medical, pharmacy, and genetics students agreed about an importance of PG as compared to their peers from other study programs $(p<0.01)$.

Our findings presented in Table 5 showed that students who believe that their study curriculum is well designed agreed that PG should be an important part of their study curriculum $(\mathrm{OR}=0.54, \mathrm{CI} 0.33-0.87, p=0.01)$. They also believe that in their future practice they should be able to identify patients that could benefit from genetic testing $(\mathrm{OR}=0.48$, CI $0.31-0.75, p=0.001)$ as well as to be able to answer patients' questions regarding $\mathrm{PG}$ and $\mathrm{PM}$ (OR $=1.70$, CI 1.01-2.82, $p=0.047$ ).

As shown in Table 6, our results suggest that the field of study significantly affects students' attitudes related to their study curriculum $(\mathrm{OR}=3.94$, CI $1.37-11.33$, $p=0.011)$ as well as influences students' wish to continue their postgraduate education in the area of personalized medicine. As compared to other respondents, it appears that the highest number of GBE students would like to continue their postgraduate education in this field $(\mathrm{OR}=14.7 \mathrm{CI} 4.31-49.9, p<0.001$, upon adjustment to students' gender, age, and level of education). 
Table 4 Students' opinion regarding the study curriculum and their future plans in pharmacogenomics

\begin{tabular}{|c|c|c|c|c|c|c|c|}
\hline & Total & $\begin{array}{l}\text { Faculty of } \\
\text { Pharmacy }\end{array}$ & $\begin{array}{l}\text { Faculty of } \\
\text { Medicine }\end{array}$ & $\begin{array}{l}\text { Genetics and } \\
\text { Bioengineering }\end{array}$ & $\begin{array}{l}\text { Faculty of } \\
\text { Health Studies }\end{array}$ & $\begin{array}{l}\text { Non- ML\&HS } \\
\text { faculties }\end{array}$ & $p^{*}$ \\
\hline \multicolumn{8}{|c|}{ Do you think that the curriculum of your study program is well designed for understanding pharmacogenomics? } \\
\hline Agree & $219(40)^{a}$ & $74(44)$ & $78(51)$ & $15(20)$ & $37(61)$ & $15(18)$ & \multirow[t]{4}{*}{$<0.01$} \\
\hline Disagree & $185(34)$ & $71(43)$ & $40(26)$ & $25(32)$ & $17(28)$ & $32(37)$ & \\
\hline Not sure & $139(26)$ & $21(13)$ & $36(23)$ & $37(48)$ & $7(11)$ & $38(45)$ & \\
\hline Total & 543 & 166 & 154 & 77 & 61 & 85 & \\
\hline \multicolumn{8}{|c|}{ Pharmacogenomics should be an important part of my study curriculum. } \\
\hline Agree & $204(38)$ & $65(39)$ & $61(39)$ & $46(71)$ & $7(11)$ & $25(29)$ & \multirow[t]{4}{*}{$<0.01$} \\
\hline Disagree & $112(21)$ & $86(52)$ & $8(5)$ & $1(1)$ & - & $17(20)$ & \\
\hline Not sure & $318(41)$ & $15(9)$ & $86(56)$ & $18(28)$ & $55(89)$ & $44(51)$ & \\
\hline Total & 534 & 166 & 155 & 65 & 62 & 86 & \\
\hline \multicolumn{8}{|c|}{ Would you like to continue your postgraduate education in the field of personalized medicine? } \\
\hline Yes & $275(53)$ & $107(65)$ & $74(48)$ & $36(55)$ & $45(74)$ & $13(16)$ & \multirow[t]{3}{*}{$<0.01$} \\
\hline No & $97(18)$ & $17(10)$ & $41(27)$ & $6(9)$ & $10(16)$ & $32(39)$ & \\
\hline Do not know & $146(29)$ & $40(25)$ & $39(25)$ & $24(36)$ & $6(10)$ & $37(45)$ & \\
\hline Total & 527 & 164 & 154 & 66 & 61 & 82 & \\
\hline
\end{tabular}

ML\&HS, Molecular Life and Health Science

${ }^{*}$ Chi-square test, Bonferroni-adjusted $p$ values

apercentage (\%)

Furthermore, our results suggest that students who believe that their study program is well designed to provide them with an adequate understanding of PG are also more willing to continue their postgraduate education in the area of personalized medicine $(\mathrm{OR}=4.68, \mathrm{CI} 2.59-8.47, p$ $<0.001$ ). Similarly, it appears that these students also believe that PG should be an important part of their study curriculum $(\mathrm{OR}=1.79 \mathrm{CI} 1.01-3.19, p=0.045)$, and this opinion is particularly affected by the level of education $(\mathrm{OR}=2.40 \mathrm{CI} 1.28-4.48, p=0.006)$.

Furthermore, as shown in Table 7, our results demonstrated an interesting difference in attitude between pharmacy students from Sarajevo and Tuzla. A significantly higher number of pharmacy students at the University of Sarajevo, who have an elective course "Pharmacogenomics and Personalized Therapy" included in their study curriculum, believe that genes influence their health $(p=0.011)$, consider having genetic test done $(p<0.05)$, and agree that PM represents a new and promising healthcare model $(p<0.001)$, as compared to their colleagues from the Faculty of Pharmacy in Tuzla whose curriculum seems to cover PG education only as a few topics built into other coursework. In addition, the higher number of pharmacy students from Sarajevo agree that PG should be an important part of their study curriculum $(p<0.001)$. All surveyed pharmacy students from the University of Tuzla disagree that PG should be an important part of their study curriculum as opposed to only $6 \%$ of pharmacy students from the University of Sarajevo who believe that PG is not essential for their education.

\section{Students' awareness about the ethical, legal, and social implications (ELSI)}

Our results showed that about $45 \%$ of all students participating in our survey are aware of different ethical aspects of genetic testing, ranging from $27 \%$ of students at the Faculty of Health Studies to $54 \%$ of pharmacy students $(p<0.01$, Table 8 and Additional file 6$)$. The highest percentage $(46 \%)$ of all respondents believed that patient privacy is the most related ethical issue to pharmacogenetic testing, while $18 \%$ believed that the key issue is data confidentiality $(p<0.01)$. Other ethical issues, such as incidental findings, racial issues, and stigma, were selected by $9 \%, 5 \%$, and $4 \%$ of students, respectively. Our results revealed that $44 \%$ of students are worried about the possibility that PG test results may be passed to the unauthorized persons, and this opinion was shared similarly across different faculties (no significant difference). When asked which of the healthcare professionals should have an access to their PG information, $75 \%$ of students believe that a physician, $50 \%$ of students selected a genetic counselor, while $35 \%$ of them believe that a pharmacist should have this information. Furthermore, approximately one third of the respondents believe that they would be disadvantaged at work or job seeking in a case of unfavorable results of genetic test. Our analysis of questions related to the social issues showed that about half of participating students would not feel "helpless" or "pessimistic" (49\%) nor they would feel "different" or "inadequate" (50\%) in case of the unfavorable test results. Students' answers regarding all 
Table 5 Students' attitudes towards continued education in pharmacogenomics

\begin{tabular}{|c|c|c|c|}
\hline \multicolumn{4}{|c|}{$\begin{array}{l}\text { Do you think that the curriculum of your study program is well designed } \\
\text { for understanding PG? }\end{array}$} \\
\hline & Model I & Model II & Model III \\
\hline & $\mathrm{OR}(\mathrm{Cl})$ & $\mathrm{OR}(\mathrm{Cl})$ & $\mathrm{OR}(\mathrm{Cl})$ \\
\hline \multicolumn{4}{|l|}{$\overline{\mathrm{Q} 1}$} \\
\hline $\begin{array}{l}\text { PG should be an } \\
\text { important part of my } \\
\text { study curriculum. }\end{array}$ & $\begin{array}{l}0.54 \\
(0.33-0.87) \\
p=0.012\end{array}$ & $\begin{array}{l}0.54 \\
(0.33-0.88) \\
p=0.014\end{array}$ & $\begin{array}{l}0.75 \\
(0.43-1.30) \\
p=0.307\end{array}$ \\
\hline \multicolumn{4}{|l|}{ Q2 } \\
\hline $\begin{array}{l}\text { In my future practice, } \\
\text { I should be able to } \\
\text { identify patients that } \\
\text { could benefit from } \\
\text { genetic testing. }\end{array}$ & $\begin{array}{l}0.48 \\
(0.31-0.75) \\
p=0.001\end{array}$ & $\begin{array}{l}0.48 \\
(0.31-0.70) \\
p=0.002\end{array}$ & $\begin{array}{l}0.57 \\
(0.35-0.91) \\
p=0.020\end{array}$ \\
\hline \multicolumn{4}{|l|}{ Q3 } \\
\hline $\begin{array}{l}\text { In my future practice, } \\
\text { I should be able to } \\
\text { answer patients' } \\
\text { questions regarding } \\
\text { PG and personalized } \\
\text { medicine. }\end{array}$ & $\begin{array}{l}1.70 \\
(1.01-2.82) \\
p=0.047\end{array}$ & $\begin{array}{l}1.71 \\
(1.02-2.87) \\
p=0.044\end{array}$ & $\begin{array}{l}1.51 \\
(0.87-2.62) \\
p=0.146\end{array}$ \\
\hline \multicolumn{4}{|l|}{ Q4 } \\
\hline $\begin{array}{l}\text { In my future practice, } \\
\text { I should be able to } \\
\text { identify drugs that would } \\
\text { require PG testing prior } \\
\text { to their administration } \\
\text { to the patient. }\end{array}$ & $\begin{array}{l}0.043 \\
(0.011-0.098) \\
p=0.121\end{array}$ & $\begin{array}{l}0.050 \\
(0.006-0.107) \\
p=0.079\end{array}$ & $\begin{array}{l}0.049 \\
(0.007-0.106) \\
p=0.086\end{array}$ \\
\hline \multicolumn{4}{|l|}{ Q5 } \\
\hline $\begin{array}{l}\text { What is your field } \\
\text { of study? }\end{array}$ & $\begin{array}{l}3.94 \\
(1.37-11.33) \\
p=0.011\end{array}$ & $\begin{array}{l}7.23 \\
(1.99-26.2) \\
p=0.003\end{array}$ & $\begin{array}{l}7.23 \\
(1.99-26.2) \\
p=0.003\end{array}$ \\
\hline
\end{tabular}

Model I: without adjustment; model II: adjusted to age and gender; model III: adjusted to age, gender, and level of education

Answer as a reference for Q1: agree; answer as a reference for Q2: agree; answer as a reference for Q3: agree; answer as a reference for Q4: agree; answer as a reference for Q5: Genetics and Bioengineering

above ELSI were similar across all participating disciplines (no significant difference). Our results presented in Table 9 showed that students who are worried about the possibility that PG test may reveal that they have additional risk factors for other diseases would also feel "different" and "inadequate" $(\mathrm{OR}=2.48, \mathrm{CI} 1.34-4.60$, $p=0.004)$. A similar finding was demonstrated upon adjustment to students' age, gender, and level of education $(\mathrm{OR}=2.15$, CI $1.13-4.10, p=0.020)$.

\section{Discussion}

This is the first study that analyzed the level of awareness and attitude towards genetic tests, pharmacogenomics, and personalized medicine among students from several different universities in Bosnia and Herzegovina $(\mathrm{BH})$. Our results showed that health and molecular life science students are generally aware of PG, and the level of awareness about personal genome testing companies
Table 6 Students' attitudes towards continued education in pharmacogenomics

Would you like to continue your postgraduate education (master, PhD, specialization) in the field of personalized medicine?

\begin{tabular}{llll}
\hline \multicolumn{5}{c}{} & Model I & Model II & Model III \\
& OR $(\mathrm{Cl})$ & OR $(\mathrm{Cl})$ & OR $(\mathrm{Cl})$ \\
\hline Q1 & & & \\
PG should be an important & 1.73 & 1.79 & 2.40 \\
part of my study curriculum. & $(0.99-3.02)$ & $(1.01-3.19)$ & $(1.28-4.48)$ \\
& $p=0.056$ & $p=0.045$ & $p=0.006$ \\
Q2 & & & \\
Do you think that the curriculum & 4.68 & 4.71 & 4.27 \\
of your study program is well & $(2.59-8.47)$ & $(2.59-8.57)$ & $(2.28-7.99)$ \\
designed for understanding PG? & $p<0.001$ & $p<0.001$ & $p<0.001$ \\
Q3 & & & \\
What is your field of study? & 14.7 & 14.1 & 16.05 \\
& $(4.31-49.9)$ & $(3.94-50.6)$ & $(4.05-63.6)$ \\
& $p<0.001$ & $p<0.001$ & $p<0.001$ \\
\hline
\end{tabular}

Model I: without adjustment; model II: adjusted to age and gender; model III: adjusted to age, gender, and level of education

Answer as a reference for Q1: agree; answer as a reference for Q2: agree;

answer as a reference for Q3: Genetics and Bioengineering

appears to be similar between medicine and pharmacy students. However, students from the Faculty of Health Studies (FHS) seem to be less aware of these companies and less interested to employ PM as the novel healthcare model as compared to pharmacy, medicine, or genetics students. Although the respondents from the other non-health- and molecular life science-related studies are also generally aware of genes influence on their health, our results suggest that the level of their awareness about personal genome testing companies is significantly lower than that of their peers from medicine, pharmacy, and genetics.

Importantly, here we also demonstrated that about $40 \%$ of pharmacy students believe that PG should be an important part of their study curriculum and more than $60 \%$ of these students would like to continue their postgraduate education in the field of personalized medicine. This is in line with the recent study, which showed that the majority of students from the eight pharmacy schools in California were aware of pharmacogenomics, agreed that PG is important for the future pharmacist, and would be interested in a residency, fellowship, and/ or career specializing PG [51]. However, Latif [8] reported that in the USA by 2005, PG was only being taught at a cursory level and highlighted the need to incorporate PG into the pharmacy curriculum. A recent survey of pharmacy students in California concluded that the presence of a stand-alone PG course did not impact student-perceived preparedness for a career in pharmacogenomics [51]. These findings are in accordance with the other studies including students from the medical schools in the UK [41] and USA [52], which also 
Table 7 Pharmacy students' awareness and opinion regarding genetic tests and pharmacogenomics

\begin{tabular}{|c|c|c|c|c|}
\hline & Total & Faculty of Pharmacy, University of Sarajevo & Faculty of Pharmacy, University of Tuzla & $p^{*}$ \\
\hline \multicolumn{5}{|c|}{ Have you heard about personal genome testing companies? } \\
\hline Yes & $95(57)^{a}$ & $53(62)$ & $42(52)$ & \multirow[t]{4}{*}{0.261} \\
\hline No & $39(24)$ & $17(20)$ & $22(27)$ & \\
\hline Do not know & $32(19)$ & $15(18)$ & $17(21)$ & \\
\hline Total & 166 & 85 & 81 & \\
\hline \multicolumn{5}{|c|}{ To what extent do you think genes influence your health? } \\
\hline Completely & $30(18)$ & $20(24)$ & $10(12)$ & \multirow[t]{5}{*}{0.011} \\
\hline Moderately & $129(78)$ & $64(75)$ & $65(80)$ & \\
\hline Not at all & $1(1)$ & - & $1(1)$ & \\
\hline Do not know & $6(4)$ & $1(1)$ & $5(6)$ & \\
\hline Total & 166 & 85 & 81 & \\
\hline \multicolumn{5}{|c|}{ Would you consider having a genetic test? } \\
\hline Yes & $85(51)$ & $51(60)$ & $34(42)$ & \multirow[t]{3}{*}{0.047} \\
\hline No & $24(14)$ & $9(11)$ & $15(18)$ & \\
\hline Not sure & $57(34)$ & $25(29)$ & $32(40)$ & \\
\hline \multicolumn{5}{|l|}{ Total } \\
\hline \multicolumn{5}{|c|}{ Do you agree that personalized medicine represents a new and promising healthcare model? } \\
\hline Agree & $116(70)$ & $78(92)$ & $38(46)$ & \multirow[t]{4}{*}{$p<0.001$} \\
\hline Disagree & $14(8)$ & $2(2)$ & $12(15)$ & \\
\hline Not sure & $37(22)$ & $5(5.9)$ & $32(39)$ & \\
\hline Total & 167 & 85 & 82 & \\
\hline \multicolumn{5}{|c|}{ Pharmacogenomics should be an important part of my study curriculum. } \\
\hline Agree & $65(39)$ & $65(76)$ & & \multirow[t]{4}{*}{$p<0.001$} \\
\hline Disagree & $86(52)$ & $5(5.9)$ & $81(100)$ & \\
\hline Not sure & $15(9)$ & $15(18)$ & & \\
\hline Total & 166 & 85 & 81 & \\
\hline \multicolumn{5}{|c|}{ Would you like to continue your postgraduate education in the field of personalized medicine? } \\
\hline Yes & $107(64)$ & $31(36)$ & $76(94)$ & \multirow[t]{3}{*}{$p<0.001$} \\
\hline No & $19(11)$ & $16(19)$ & $3(4)$ & \\
\hline Do not know & $40(24)$ & $38(45)$ & $2(2)$ & \\
\hline Total & 166 & 85 & 81 & \\
\hline
\end{tabular}

*Chi-square test, Bonferroni-adjusted $p$ values

aPercentage (\%)

clearly indicated that inadequate education at undergraduate and postgraduate medical programs is an important obstacle to more broad use of PG. A recent study performed at the Stanford School of Medicine showed that almost all students taking a course in personalized medicine believed that physicians are not trained to interpret results of PG tests and thus are not able to effectively practice PM [52]. In line with this study, more than a third of the total number of students participating in our survey disagree that the curriculum of their study program is well designed to understand PG, suggesting that the majority of faculties do not have PG-related courses implemented in their curricula.
Similar to our finding that $52 \%$ of pharmacy students disagree that their study program is well designed for understanding PG, half of the pharmacy students at the University of Minnesota also argued that their curriculum is not well designed to grasp pharmacogenomics [38]. Interestingly, in contrast to the pharmacy students from the University of Tuzla whose curriculum covers PG topics cursorily, usually not more than a week in a semester as a part of other coursework based on their current curriculum (http://frmf.untz.ba/web/bs/integri sani-i-i-ii-ciklus/), pharmacy students from the University of Sarajevo think that their curriculum is well designed to understand PG and PM. The Faculty of 
Table 8 Students' awareness and opinion regarding the ethical, legal, and social implications (ELSI)

\begin{tabular}{|c|c|c|c|c|c|c|c|}
\hline & Total & $\begin{array}{l}\text { Faculty of } \\
\text { Pharmacy }\end{array}$ & $\begin{array}{l}\text { Faculty of } \\
\text { Medicine }\end{array}$ & $\begin{array}{l}\text { Genetics and } \\
\text { Bioengineering }\end{array}$ & $\begin{array}{l}\text { Faculty of Health } \\
\text { Studies }\end{array}$ & Non- ML\&HS & $p^{*}$ \\
\hline \multicolumn{8}{|l|}{ Ethical } \\
\hline \multicolumn{8}{|c|}{ Are you aware of the different ethical aspects of genetic testing? } \\
\hline Yes & $244(45)^{a}$ & $90(54)$ & $50(36)$ & $28(43)$ & $17(27)$ & $26(30)$ & \multirow[t]{4}{*}{$<0.01$} \\
\hline No & $155(29)$ & $32(19)$ & $60(43)$ & $22(34)$ & $32(50)$ & $33(38)$ & \\
\hline Not sure & $139(26)$ & $44(27)$ & $30(21)$ & $15(23)$ & $15(23)$ & $27(32)$ & \\
\hline Total & 538 & 166 & 140 & 65 & 64 & 86 & \\
\hline \multicolumn{8}{|c|}{ What ethical issues do you believe might be related to genetic or PG testing? } \\
\hline Patient privacy & $237(46)$ & $88(40)$ & $63(34)$ & $29(38)$ & $30(41)$ & $27(29)$ & \multirow[t]{7}{*}{$<0.01$} \\
\hline Data confidentiality & $91(18)$ & $82(37)$ & $56(30)$ & $14(18)$ & $13(18)$ & $8(8)$ & \\
\hline Racial issues & $27(5)$ & $10(5)$ & $4(3)$ & $2(3)$ & $12(17)$ & $9(10)$ & \\
\hline Stigma & $20(4)$ & $7(3)$ & $17(9)$ & - & - & $3(3)$ & \\
\hline Incidental findings & $47(9)$ & $21(9)$ & $21(11)$ & $9(12)$ & $9(12)$ & $8(8)$ & \\
\hline Other & $93(18)$ & $14(6)$ & $24(13)$ & $21(28)$ & $9(12)$ & $39(42)$ & \\
\hline Total & 515 & 222 & 185 & 75 & 73 & 94 & \\
\hline \multicolumn{8}{|l|}{ Legal } \\
\hline \multicolumn{8}{|c|}{ Are you worried about the possibility that the results of a PG test may be passed to unauthorized persons? } \\
\hline Worried & $238(44)$ & $71(43)$ & $69(44)$ & $30(46)$ & $24(37)$ & $44(51)$ & \multirow[t]{3}{*}{1.0} \\
\hline Not worried & $190(35)$ & $65(39)$ & $60(38)$ & $24(36)$ & $21(33)$ & $20(23)$ & \\
\hline No opinion & $112(21)$ & $30(18)$ & $29(18)$ & $12(18)$ & $19(30)$ & $22(26)$ & \\
\hline Total & 540 & 166 & 158 & 66 & 64 & 86 & \\
\hline
\end{tabular}

In case unfavorable test results should be disclosed, do you believe that you would be disadvantaged at work or job seeking?

\begin{tabular}{|c|c|c|c|c|c|c|}
\hline Yes & $165(31)$ & $45(27)$ & $49(31)$ & $26(39)$ & $21(35)$ & $24(28)$ \\
\hline No & $219(41)$ & $86(51)$ & $71(45)$ & $17(26)$ & $15(25)$ & $30(35)$ \\
\hline Not sure & $152(28)$ & $38(22)$ & $38(24)$ & $23(35)$ & $24(40)$ & $32(37)$ \\
\hline Total & 536 & 169 & 158 & 66 & 60 & 86 \\
\hline
\end{tabular}

Social

In case of an unfavorable test result, do you believe you would feel "helpless" or "pessimistic"?

$\begin{array}{lllllll}\text { Yes } & 174(33) & 63(38) & 40(25) & 26(39) & 18(29) & 27(32) \\ \text { No } & 265(49) & 69(42) & 93(58) & 35(53) & 32(52) & 36(42) \\ \text { Not sure } & 98(18) & 34(20) & 25(16) & 5(8) & 12(19) & 22(26) \\ \text { Total } & 537 & 166 & 158 & 66 & 62 & 85\end{array}$

In case of an unfavorable test result, do you believe you would feel "different" or "inadequate"?

\begin{tabular}{|c|c|c|c|c|c|c|c|}
\hline Yes & $152(28)$ & $51(31)$ & $32(20)$ & $25(38)$ & $19(31)$ & $25(30)$ & 0.100 \\
\hline No & $268(50)$ & $84(50)$ & $95(60)$ & $32(48)$ & $27(44)$ & $30(36)$ & \\
\hline Not sure & $115(22)$ & $31(19)$ & $31(20)$ & $9(14)$ & $15(25)$ & $29(34)$ & \\
\hline Tot & 535 & 166 & 158 & 66 & 61 & 84 & \\
\hline
\end{tabular}

ML\&HS, Molecular Life and Health Science

${ }^{*}$ Chi-square test, Bonferroni-adjusted $p$ values

apercentage (\%)

Pharmacy in Sarajevo implemented changes in their curriculum in 2012. Based on our knowledge and information available at the Faculty's website (http:// ffsa.unsa.ba/wp-content/uploads/2014/03/ECTS-katalog-2 015.pdf), so far in BH only this Faculty included an elective course Pharmacogenomics and Personalized
Therapy in the biomedical study course. In addition, pharmacy students from Sarajevo have a lot of subject education built into their other coursework. This is may be the reason why student pharmacists from Sarajevo had more positive attitude and future plans towards PG, while the majority of the pharmacy 
Table 9 Students' opinion regarding the confidentiality and data privacy in pharmacogenomic testing

\begin{tabular}{|c|c|c|c|}
\hline & Model I & Model II & Model III \\
\hline & $\mathrm{OR}(\mathrm{Cl})$ & $\mathrm{OR}(\mathrm{Cl})$ & $\mathrm{OR}(\mathrm{Cl})$ \\
\hline \multicolumn{4}{|c|}{$\begin{array}{l}\text { In case of an unfavorable test result, do you believe that you would feel } \\
\text { "different" or "inadequate"? }\end{array}$} \\
\hline \multicolumn{4}{|l|}{ Q1 } \\
\hline $\begin{array}{l}\text { Are you worried about } \\
\text { the possibility that a } \\
\text { pharmacogenomics test } \\
\text { may reveal that you have } \\
\text { additional risk factors for } \\
\text { other diseases? }\end{array}$ & $\begin{array}{l}2.48 \\
(1.34-4.60) \\
p=0.004\end{array}$ & $\begin{array}{l}2.17 \\
(1.15-4.09) \\
p=0.017\end{array}$ & $\begin{array}{l}2.15 \\
(1.13-4.10) \\
p=0.020\end{array}$ \\
\hline
\end{tabular}

Model I: without adjustment; model II: adjusted to age and gender; model III: adjusted to age, gender, and level of education

Answer as a reference for Q1: yes

students from Tuzla disagree that PG should be an important part of their study curriculum.

Students of the Genetics and Bioengineering program at the International University of Sarajevo have special PG topics included in the syllabus of several undergraduate and graduate courses, including courses Pharmaceutical Biotechnology and Omics Technologies. Interestingly, more than $70 \%$ of GBE students agree that PG should be an important part of their study curriculum and more than half of them would like to continue their postgraduate education in the field of personalized medicine. Furthermore, as expected, in contrast to students from HS and MLS studies, half of students from other non-related study programs are not interested to continue their education in the field of pharmacogenomics and personalized medicine. Thus, in line with previous studies [38, 51], our results confirmed that if students do not gain enough PG knowledge during their studies, that would affect their attitudes towards PG as well as their future interest for this area of research or professional practice. Specifically, McCullough et al. [16] showed that pharmacists included in their study lacked the knowledge and self-confidence to act properly based on the results of PG testing. However, an education emphasizing medical applications of PG can significantly increase students' knowledge and comfort in their PG practice. Recently, Pisanu et al. [53] investigated the discrepancy in PG education in Southeast Europe and recommended that PG should be thought as a stand-alone course or at least as a part of existing genetics courses. The lack of education and clinical guidelines appear to be among the major barriers perceived by participants towards the clinical application of PG [51].

It is expected that PG will continue to evolve over time and become one of the most relevant aspects of patient care. For this reason, it is of key importance to increase the number of professional practitioners in this new and expanding area of PG and to modify the current curricula to increase students' knowledge and interests. The survey performed in the UK in 2008 found that typically $2-8 \mathrm{~h}$ of PG teaching were included in the pharmacology curricula of UK medical schools [41]. Previous studies have shown that incorporating active learning experiences in PG would increase student interests [54]. Additional innovative learning methods in PG have been recently adopted, such as Pharmacogenomics Education Program 3 (PharmGenEd $\left.{ }^{\mathrm{TM}}\right)$ open online courses [9] and personal genotyping [52, 55, 56]. When teaching PG through practical applications, students learn to use genetic information in the framework of medication management, allowing them to understand the significance of PG applications in clinical practice [51].

As our results indicate, $\mathrm{BH}$ students are interested to continue their education in PG. They would like to learn more about pharmacogenomics, its clinical examples and benefits, as well as about ELSI and future developments in this field. Students consider performing genetic tests in their future practice to optimize therapy for their patients as well as answering patients' questions regarding PG and personalized medicine. Interestingly, our results suggest that the field of study significantly influences students' wish to continue their education in this area. This is in line with the previous studies which indicated that healthcare students believe that PG is important for patient care $[16,40]$ and that they should have the knowledge to employ genetic tests results to optimize therapy and educate their patients [38].

Students participating in our survey have shown to be aware of different ethical aspects of genetic testing. Interestingly, our results demonstrated that the majority of students appear to be concerned about the patient's privacy and data confidentiality, followed by other ethical issues, such as autonomy, trust, beneficence relating to incidental findings, racial issues, and stigma. The majority of participants in our survey believe that the physician, pharmacist, and genetic counselor should have an access to their PG information. If genetic information is inappropriately disclosed, individuals may suffer from embarrassment, stigma, and discrimination, and these issues are recently considered as the key aspects of respecting confidentiality [25]. This is increasingly a salient point with developments and prevalence of information and communication technology, especially in the context of health, with emerging EU regulations in context of data sharing. Information and tools that were previously accessible to physicians only under controlled clinical setting within the last decade have been made freely available through the increasing variety of the direct-to-consumer (DTC) genetic tests on the Internet and social networks, often without the public's ability to understand the health risk information that are sold without genetic counseling $[57,58]$. This issue is 
particularly important in the low- and middle-income countries, where the use of commercial genomics and DTC tests might not be adequately regulated yet.

Our results suggest that students from non-HS- and non-MLS-related faculties, including architecture, psychology, industrial, mechanical, electrical engineering, and others, are also generally aware of genes influence on their own health as well as about benefits of PM-based healthcare model. About half of these students agree that personalized medicine represents a new and promising healthcare model, and the majority of them would consider having a genetic test done to find out what illnesses they might develop in the future. However, their awareness of personal genome testing companies is lower as well as their readiness to contact a personal genome testing company and order a PG test, as compared to their peers from medicine, pharmacy, and genetics. Furthermore, these students from non-HSand non-MLS-related faculties appear to be less aware regarding the potential ethical implications of PG testing, as compared to the students from medicine and pharmacy. These findings may indicate the significance of educating the public about genomics and its relevant bioethical implications. As recently suggested by Dressler et al. [59], roundtable discussions, a body of experts' discussions, workshops, and symposia are needed to bring together key interdisciplinary stakeholders in academia, government, profit, and nonprofit organizations to create programs of genomic education for the public. Such efforts can lead to enhanced knowledge and widespread acceptance of PG.

Interestingly, our findings revealed that almost half of all respondents are worried about the possibility that PG test results may be passed to the unauthorized persons, and this opinion was shared similarly across different study programs. Students who are worried about the possibility that PG test may reveal that they have additional risk factors for other diseases would also feel "different" and "inadequate" in case of the unfavorable test results. Otherwise, about half of respondents would not feel "helpless" or "pessimistic," nor they would not feel "different" or "inadequate." This is in line with the previous study, which indicated that every individual would respond in a different way to the genetic test results, and it is considered essential for patients to have a proper counseling to help them understand the meaning and significance of the test results related to their own health $[60,61]$. This also emphasizes the importance of sociological disciplines in public perceptions of pharmacogenomics and personalized medicine in order to examine and understand better the society's needs, concerns, and attitudes towards the utilization of PG testing and its wider clinical implementation as well as to be an asset in instituting policies and regulating the use of genetic information. This is in line with the findings of the recent survey of the general public in Belgium on genetics and genetic testing [62], which indicated that recognizing the attitudes and concerns of the general public is the key in ensuring ethically reliable and socially acceptable application of new genetic technologies. Sociology students should be also approached to expand such studies of people's reactions to genetics and PM/PG, where it would be pertinent to compare expected attitudes with actual attitudes upon receiving results of genetic tests [22].

An important strength of our study was that we recruited a variety of health science students across the nation within three different settings (medicine, pharmacy, health studies), genetics students, and students from other non-molecular life and non-health science programs. Another key aspect of our study was that, for the first time in $\mathrm{BH}$, we have investigated students' perceptions regarding their knowledge, skills, and attitudes towards pharmacogenomics and personalized medicine as well as their ethical, legal, and social implications. In addition, we compared opinions and attitudes of students who were exposed vs. students who were non-exposed to the PG course that further strengthens our results. Although our survey explored students' interest in learning more about PG, we did not investigate which teaching tools students would favor in order to determine the most effective way to educate students in PG. Another limitation is that the survey which we designed assessed perceived (or self-reported) understanding and skills in pharmacogenomics and personalized medicine, with the limited possibility to evaluate actual students' knowledge and capabilities. Lastly, survey tools that employ Likert scale are prone to central tendency bias due to selection of neutral answers. However, the potential impact of this type of bias on our results is probably small due to low percentage of neutral answers in the majority of our questions. Notwithstanding these limitations, our study will offer an important reference point for future comparative studies between different regions and countries as well as between different disciplines.

\section{Conclusions}

Here we investigated for the first time students' perceptions about pharmacogenomics and personalized medicine across the nation and various study programs that was, based on our knowledge, never studied before in Bosnia and Herzegovina. Our results show that most of the students participating in our survey, other than pharmacy students from Sarajevo, believe that they do not have well-designed curricula for understanding and practicing PG. The large number of students enrolled in molecular life and health sciences clearly expressed their wish to be more educated in this field. This implies the need for the development of study programs in the area 
of PG in order to equip future providers with the knowledge, skills, and attitude required to practice personalized medicine. This could also further highlight the need for increased genetic literacy education throughout high school levels throughout Europe and beyond. In order to accomplish this important goal, it would be pertinent to enhance collaboration between universities, healthcare institution, and governing bodies to incorporate more training and continued education topics related to pharmacogenomics and genetic testing. There could also be a potential here for increasing the number of interdisciplinary events or training between different disciplines, such as those highlighted in this study, both for students and for educators and researchers in order to discuss various forms of curriculum development. Thus, expanding the pharmacogenomic path of biomedical education represents an essential step for ensuring the widespread clinical implementation of personalized medicine.

\section{Additional files}

\section{Additional file 1: The survey questionnaire-the file describes the} questionnaire that was employed in this study. (PDF $295 \mathrm{~kb}$ )

Additional file 2: Students' awareness about pharmacogenomics-the table represents $p$ values calculated with chi-square test between each faculty, based on the first question from Table 2. (PDF $50 \mathrm{~kb}$ )

Additional file 3: Levels of students' awareness about genetic tests and pharmacogenomics - the table represents $p$ values calculated with chi-square test between each faculty, based on the fourth question from Table 2. (PDF 204 kb)

Additional file 4: Students' opinion regarding the study curriculum and their future plans in pharmacogenomics - the table represents $p$ values calculated with chi-square test between each faculty, based on the first question from Table 4. (PDF $134 \mathrm{~kb}$ )

Additional file 5: Students' opinion regarding the study curriculum and their future plans in pharmacogenomics - the table represents $p$ values calculated with chi-square test between each faculty, based on the third question from Table 4. (PDF $134 \mathrm{~kb}$ )

Additional file 6: Students' awareness and opinion regarding the ethical, legal, and social issues - the table represents $p$ values calculated with chi-square test between each faculty, based on the first question from Table 8. (PDF $133 \mathrm{~kb}$ )

\section{Abbreviations \\ BH: Bosnia and Herzegovina; Cl: Confidence intervals; DTC: Direct-to-consumer ELSI: Ethical, legal, and social implications; FDA: Food and Drug Administration; FHS: Faculty of Health Studies; GBE: Genetics and Bioengineering; HS: Health Studies; IBM SPSS ${ }^{\circledR 23}$ : IBM Statistical Package for Social Science, Version 23; MLS: Molecular and life sciences; OR: Odds ratio; PG: Pharmacogenomics; PharmGenEd ${ }^{\text {TM. }}$ : Pharmacogenomics Education Program; \\ PharmGKB: Pharmacogenomics Knowledgebase; PM: Personalized medicine}

\section{Acknowledgements}

The authors would like to thank all students participating in this survey, as well as all managerial and administrative staff for the survey distribution in participating institutions. We thank Dr. Emin Tahirovic for his kind help with the statistical analysis. This article is based upon work from COST Action IS1303 "Citizen's Health through public-private Initiatives: Public health, Market and Ethical perspectives," supported by COST (European Cooperation in Science and Technology) (http://www.cost.eu).

\section{Funding}

This study was partially funded by the grants received from the Council of Ministers of BH/Ministry of Civil Affairs $\mathrm{BH}$, awarded to SS.

\section{Availability of data and materials}

The data supporting the conclusions of this article are included within the article and its additional files.

\section{Authors' contributions}

MW, SS, and CD participated in the development of the questionnaire. LM, $\mathrm{CD}, \mathrm{AM}$, and $\mathrm{NH}$ were involved in the survey distribution and data acquisition. LM was responsible for the statistical analysis and has made substantial contribution to the data interpretation. MA was involved in the statistical analysis. LM and BA were engaged in the writing of the initial draft of the manuscript. FBA helped in the data collection process. MW and OF revised the manuscript critically for its important intellectual content. SS conceived and designed the study, coordinated and supervised the study, provided its financial support, interpreted data, and revised the manuscript critically for its important intellectual content. All authors read and approved the final manuscript.

\section{Authors' information}

Sabina Semiz, PhD, is a Professor in Genetics and Bioengineering at the International University of Sarajevo (IUS). She is the Head of the Bosnia and Herzegovina Unit of the UNESCO Chair in Bioethics, Chair of the Cambridge Bioethics Education Network Working Group, and a member of the Management Committee of the CHIP ME COST Action IS1303 "Citizen's Health through public-private Initiatives: Public health, Market and Ethical perspectives." Matthias Wjst, PhD, and Oliver Feeney, PhD, (Researcher in Political Theory and Bioethics at the Centre of Bioethical Research and Analysis) are members of the Management Committee and Working Group 2 and Working Group 3 of the CHIP ME COST Action IS1303. Faruk Berat Akcesme, PhD, and Betul Akcesme, PhD, were Assistant Professors at the Genetics and Bioengineering Program at FENS, and they recently joined the Faculty of Medicine, University of Health Sciences, Istanbul, Turkey. Lejla Mahmutovic and Muhamed Adilovic are PhD students, while Camil Durakovic, Aida Maric, and Nour Hamad were master students at the IUS. Aida Maric recently started her PhD program at the Plant Biotechnology Department, Faculty of Pharmacy and Food Sciences, at the University of Barcelona, Spain.

Ethics approval and consent to participate

The study was approved by the Ethical Committee of the International University of Sarajevo (protocol number: IUS-REC-01-575/2017). Each participant was informed of the objectives of the study and informed consent was obtained from all participants.

\section{Consent for publication}

Not applicable.

\section{Competing interests}

The authors declare that they have no competing interests.

\section{Publisher's Note}

Springer Nature remains neutral with regard to jurisdictional claims in published maps and institutional affiliations.

\footnotetext{
Author details

${ }^{1}$ Faculty of Engineering and Natural Sciences, International University of Sarajevo, Hrasnicka cesta 15, 71210 llidza, Sarajevo, Bosnia and Herzegovina. ${ }^{2}$ Department of Medical Biology, Faculty of Medicine, University of Health Sciences, Istanbul, Turkey. ${ }^{3}$ Department of Biostatistics and Medical Informatics, Faculty of Medicine, University of Health Sciences, Istanbul, Turkey. ${ }^{4}$ Helmholtz Zentrum Muenchen, German Research Center for Environmental Health $(\mathrm{GmbH})$, Ingolstaedter Landstraße 1, D-85764 Munich, Neuherberg, Germany. ${ }^{5}$ Centre of Bioethical Research and Analysis, National University of Ireland (Galway), Galway, Republic of Ireland.
} 
Received: 29 June 2018 Accepted: 28 October 2018

Published online: 14 November 2018

\section{References}

1. Abul-Husn NS, et al. Implementation and utilization of genetic testing in personalized medicine. Pharmgenomics Pers Med. 2014;7:227-40.

2. Manolio TA, et al. Implementing genomic medicine in the clinic: the future is here. Genet Med. 2013;15(4):258-67.

3. McCarthy JJ, et al. Genomic medicine: a decade of successes, challenges, and opportunities. Sci Transl Med. 2013;5(189):189sr4.

4. Shuldiner AR, et al. The pharmacogenomics research network translational pharmacogenetics program: overcoming challenges of real-world implementation. Clin Pharmacol Ther. 2013:94(2):207-10.

5. Phillips E, Mallal S. Successful translation of pharmacogenetics into the clinic: the abacavir example. Mol Diagn Ther. 2009;13(1):1-9.

6. Goldspiel BR, et al. Integrating pharmacogenetic information and clinical decision support into the electronic health record. J Am Med Inform Assoc. 2014;21(3):522-8.

7. Collins FS, Morgan M, Patrinos A. The Human Genome Project: lessons from large-scale biology. Science. 2003;300(5617):286-90.

8. Latif DA. Pharmacogenetics and pharmacogenomics instruction in schools of pharmacy in the USA: is it adequate? Pharmacogenomics. 2005;6(4):317-9.

9. Ma JD, Lee KC, Kuo GM. A massive open online course on pharmacogenomics: not just disruptive innovation but a possible solution. Pharmacogenomics. 2013;14(10):1125-7.

10. Collins FS, Varmus H. A new initiative on precision medicine. N Engl J Med. 2015;372(9):793-5.

11. Wang B, Canestaro WJ, Choudhry NK. Clinical evidence supporting pharmacogenomic biomarker testing provided in US Food and Drug Administration drug labels. JAMA Intern Med. 2014;174(12):1938-44.

12. Johnson JA. Pharmacogenetics in clinical practice: how far have we come and where are we going? Pharmacogenomics. 2013;14(7):835-43.

13. Olivier C, Williams-Jones B. Global pharmacogenomics: where is the research taking us? Glob Public Health. 2014;9(3):312-24.

14. Elewa $\mathrm{H}$, et al. A survey on the awareness and attitude of pharmacists and doctors towards the application of pharmacogenomics and its challenges in Qatar. J Eval Clin Pract. 2015:21(4):703-9.

15. Obara T, et al. Awareness regarding clinical application of pharmacogenetics among Japanese pharmacists. Pharmgenomics Pers Med. 2015;8:35-41.

16. McCullough KB, et al. Assessment of the pharmacogenomics educational needs of pharmacists. Am J Pharm Educ. 2011;75(3):51.

17. Carlberg C. The need for education in personalized medicine. Personalized Med. 2012;9(2):147-50

18. Dickinson BD. Pharmacogenomic knowledge gaps and educational resource needs among physicians in selected specialties. Pharmacogenomics Personalized Med. 2014;7:145-62.

19. Frueh FW, Gurwitz D. From pharmacogenetics to personalized medicine: a vital need for educating health professionals and the community, Pharmacogenomics. 2004;5(5):571-9.

20. Salari $P$, Larijani B. Ethical issues surrounding personalized medicine: a literature review. Acta Med Iran. 2017;55(3):209-17.

21. Javitt GH. Policy implications of genetic testing: not just for geneticists anymore. Adv Chronic Kidney Dis. 2006;13(2):178-82.

22. Corrigan OP. Pharmacogenetics, ethical issues: review of the Nuffield Council on Bioethics Report. J Med Ethics. 2005;31(3):144-8.

23. Rothstein MA, Epps PG. Ethical and legal implications of pharmacogenomics. Nat Rev Genet. 2001;2(3):228-31.

24. Motulsky AG. Bioethical problems in pharmacogenetics and ecogenetics. Hum Genet Suppl. 1978;1:185-92.

25. Brothers KB, Rothstein MA. Ethical, legal and social implications of incorporating personalized medicine into healthcare. Per Med. 2015;12(1):43-51.

26. Lala $M$, et al. Genetics-based pediatric warfarin dosage regimen derived using pharmacometric bridging. J Pediatr Pharmacol Ther. 2013;18(3):209-19.

27. Egalite N, Ozdemir V, Godard B. Pharmacogenomics research involving racial classification: qualitative research findings on researchers' views, perceptions and attitudes towards socioethical responsibilities. Pharmacogenomics. 2007:8(9):1115-26.

28. Vogenberg FR, Barash Cl, Pursel M. Personalized medicine: part 2: ethical, legal, and regulatory issues. P T. 2010;35(11):624-42.

29. Netzer C, Biller-Andorno N. Pharmacogenetic testing, informed consent and the problem of secondary information. Bioethics. 2004;18(4):344-60.
30. Spector-Bagdady K. "The Google of healthcare": enabling the privatization of genetic bio/databanking. Ann Epidemiol. 2016;26(7):515-9.

31. Niemiec $E$, Howard HC. Ethical issues in consumer genome sequencing: use of consumers' samples and data. Appl Transl Genom. 2016;8:23-30.

32. Trinidad SB, et al. "Getting off the bus closer to your destination": patients' views about pharmacogenetic testing. Perm J. 2015;19(3):21-7.

33. Mardis ER. A decade's perspective on DNA sequencing technology. Nature. 2011;470(7333):198-203.

34. Manolio TA, et al. Global implementation of genomic medicine: we are not alone. Sci Transl Med. 2015;7(290):290ps13.

35. Ndebele P, Musesengwa R. Will developing countries benefit from their participation in genetics research? Malawi Med J. 2008;20(2):67-9.

36. Murphy JE, et al. Pharmacogenomics in the curricula of colleges and schools of pharmacy in the United States. Am J Pharm Educ. 2010;74(1):7.

37. Ormond KE, et al. Medical and graduate students' attitudes toward personal genomics. Genet Med. 2011;13(5):400-8.

38. Moen M, Lamba J. Assessment of healthcare students' views on pharmacogenomics at the University of Minnesota. Pharmacogenomics. 2012;13(13):1537-45.

39. Jr JP, et al. Pre-graduate and post-graduate education in personalized medicine in the Czech Republic: statistics, analysis and recommendations. EPMA J. 2014;5(1):22.

40. Gurwitz D, et al. Pharmacogenomics education: International Society of Pharmacogenomics recommendations for medical, pharmaceutical, and health schools deans of education. Pharmacogenomics J. 2005;5(4):221-5.

41. Higgs JE, et al. Pharmacogenetics education in British medical schools. Genomic Med. 2008;2(3-4):101-5.

42. Cavallari LH, et al. Institutional profile: University of Florida Health Personalized Medicine Program. Pharmacogenomics. 2017;18(5):421-6.

43. Patrinos GP, Katsila T. Pharmacogenomics education and research at the Department of Pharmacy, University of Patras, Greece. Pharmacogenomics. 2016:17(17):1865-72.

44. Eden C, et al. Medical student preparedness for an era of personalized medicine: findings from one US medical school. Per Med. 2016:13(2):129-41.

45. Krynetskiy E. Institutional profile: Jayne Haines Center for Pharmacogenomics and Drug Safety: educating future generations of healthcare professionals. Pharmacogenomics. 2013;14(5):465-8.

46. Ceric T, et al. Investigation of IVS14 + 1G > A polymorphism of DPYD gene in a group of Bosnian patients treated with 5-fluorouracil and capecitabine. Bosn J Basic Med Sci. 2010;10(2):133-9.

47. Hadzagic-Catibusic F, et al. Effects of carbamazepine and valproate on serum aspartate aminotransferase, alanine aminotransferase and gamma glutamyltransferase in children. Med Arch. 2017;71(4):239-42.

48. Dujic T, et al. Organic cation transporter 1 variants and gastrointestinal side effects of metformin in patients with type 2 diabetes. Diabet Med. 2016 33(4):511-4.

49. Zhou $\mathrm{K}$, et al. Variation in the glucose transporter gene SLC2A2 is associated with glycemic response to metformin. Nat Genet. 2016;48(9):1055-9.

50. Semiz S, et al. Analysis of CYP2C9*2, CYP2C19*2, and CYP2D6*4 polymorphisms in patients with type 2 diabetes mellitus. Bosn J Basic Med Sci. 2010;10(4):287-91.

51. Vaksman $\mathrm{N}$, et al. The impact of incorporating of pharmacogenomics into the pharmacy curriculum on student interest. Pharm Educ. 2012;12.

52. Salari $\mathrm{K}$, et al. Evidence that personal genome testing enhances student learning in a course on genomics and personalized medicine. PLoS One. 2013;8(7):e68853.

53. Pisanu C, et al. Assessment of the pharmacogenomics educational environment in Southeast Europe. Public Health Genomics. 2014;17(5-6):272-9.

54. Knoell DL, et al. A genotyping exercise for pharmacogenetics in pharmacy practice. Am J Pharm Educ. 2009;73(3):43.

55. Adams SM, et al. Advancing pharmacogenomics education in the Core PharmD curriculum through student personal genomic testing. Am J Pharm Educ. 2016;80(1):3.

56. Frick $A$, et al. Transitioning pharmacogenomics into the clinical setting: training future pharmacists. Front Pharmacol. 2016;7:241.

57. Borry P, Cornel MC, Howard HC. Where are you going, where have you been: a recent history of the direct-to-consumer genetic testing market. J Community Genet. 2010;1(3):101-6.

58. Collins RE, Wright AJ, Marteau TM. Impact of communicating personalized genetic risk information on perceived control over the risk: a systematic review. Genet Med. 2011;13(4):273-7. 
59. Dressler $L G$, et al. Genomics education for the public: perspectives of genomic researchers and ELSI advisors. Genet Test Mol Biomarkers. 2014; 18(3):131-40.

60. Winkler EC, Wiemann S. Findings made in gene panel to whole genome sequencing: data, knowledge, ethics-and consequences? Expert Rev Mol Diagn. 2016;16(12):1259-70.

61. Howard HC, Borry P. Survey of European clinical geneticists on awareness, experiences and attitudes towards direct-to-consumer genetic testing. Genome Med. 2013;5(5):45.

62. Chokoshvili $D$, et al. Public views on genetics and genetic testing: a survey of the general public in Belgium. Genet Test Mol Biomarkers. 2017;21(3): 195-201.

Ready to submit your research? Choose BMC and benefit from:

- fast, convenient online submission

- thorough peer review by experienced researchers in your field

- rapid publication on acceptance

- support for research data, including large and complex data types

- gold Open Access which fosters wider collaboration and increased citations

- maximum visibility for your research: over $100 \mathrm{M}$ website views per year

At $\mathrm{BMC}$, research is always in progress.

Learn more biomedcentral.com/submissions 